\title{
Advanced control of direct-driven PMSG generator in wind turbine system
}

\author{
Piotr Gajewski, Krzysztof Pieńkowski \\ Department of Electrical Machines, Drives and Measurements \\ Wroclaw University of Science and Technology \\ Wybrzeże Wyspiańskiego 27, 50-370 Wrocław, Poland \\ e-mail: piotr.gajewski/krzysztof.pienkowski@pwr.edu.pl
}

(Received: 08.09.2015, revised: 21.07.2016)

\begin{abstract}
The paper presents the advanced control system of the wind energy conversion with a variable speed wind turbine. The considered system consists of a wind turbine with the permanent magnet synchronous generator (PMSG), machine side converter (MSC), grid side converter (GSC) and control circuits. The mathematical models of a wind turbine system, the PMSG generator and converters have been described. The control algorithms of the converter systems based on the methods of vector control have been applied. In the advanced control system of the machine side converter the optimal MPPT control method has been used. Additionally the pitch control scheme is included in order to achieve the limitation of maximum power and to prevent mechanical damage of the wind turbine. In the control system of the grid side converter the control of active and reactive power has been applied with the application of Voltage Oriented Control (VOC). The performance of the considered wind energy system has been studied by digital simulation. The results of simulation studies confirmed the good effectiveness of the considered wind turbine system and very good performance of the proposed methods of vector control and control systems.
\end{abstract}

Key words: wind turbine, PMSG generator, MPPT control, pitch control, simulation studies

\section{Introduction}

The applications of wind energy conversion systems (WECS) have increased significantly in recent years. The increasing trend is to stimulate research in the field of energy conversion in order to optimize the obtaining of the largest values of energy from wind turbines. The applied systems of wind turbines can be classified into fixed speed and variable speed turbines. The variable speed turbine systems are now more often applied then the systems with fixed speed. The main advantages of variable speed systems are: increasing the production of wind energy, the ability to achieve maximum energy conversion efficiency and reduction of mechanical stresses [1-4]. 
Most of the main wind turbine manufacturers develop systems based on variable speed wind turbines. The performance of the wind energy systems can be greatly enhanced with the use of a full-capacity converter system [1-5]. With the use of these types of power converter systems, the generator is fully decoupled from the grid and can operate in full speed range. In these modern types of wind energy conversion systems the permanent magnet synchronous generators (PMSG) have been widely used.

The PMSG generator can be constructed with a large number of poles and can be operated as the direct-driven system without a gearbox. This results in a reduction of installation and maintenance costs and provides an advantage over the other types of generators. Design, construction and control of wind turbines with permanent magnet synchronous generators require the knowledge of electromechanical and electromagnetic phenomena occurring in these systems.

In wind power systems with synchronous generators the power converters should be applied in order to convert the electrical energy produced by the generator. A typical wind power system configuration has been presented in Figure 1. The figure shows the system of directly driven or geared driven PMSG generator, which is connected to the AC grid via a full scale back-to-back converter system. In the developed topology, the machine side converter (MSC) can control the speed and the electromagnetic torque of the PMSG generator, while the grid side converter (GSC) is responsible for keeping the constant voltage in the DC-link and for the control of active and reactive power delivered to the $\mathrm{AC}$ grid.

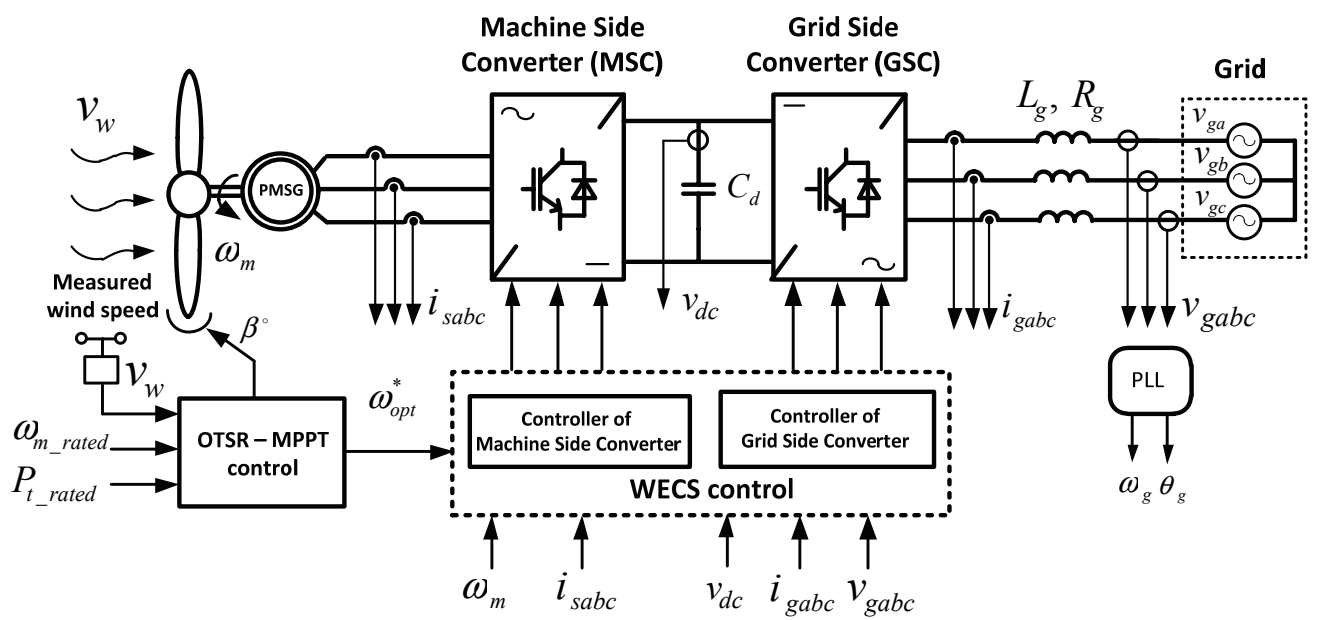

Fig. 1. The scheme of variable speed wind turbine system with direct-driven PMSG generator and back-to-back converter system

In the paper the dynamic modelling of the variable speed wind turbine system with the direct-driven PMSG and MPPT (Maximum Power Point Tracking) control is considered. In the control algorithms with MPPT three basic methods described below have been developed [4]. 
The first method of MPPT is based on the characteristics of turbine power versus wind speed $[6,7]$. According to the turbine power curve, the values of maximum power that can be produced have been determined. The measurement of wind speed by using a wind speed sensor is necessary in this control method. The signal of reference wind turbine power is sent to the control system of the machine side converter and is compared with the signal of the measured turbine power.

The second method of MPPT is related to the optimal control of PMSG torque [8, 9]. In this method the maximum of generated turbine power can be achieved by controlling the torque of PMSG. The aim of this method is obtaining of desired torque by measure of angular generator speed. This speed is used to calculate the reference of the turbine torque. The coefficient of optimal torque $K_{\mathrm{opt}}$ can be calculated according to the rated parameters of the PMSG and wind turbine.

The third method of MPPT is related to the control of the optimal tip speed ratio control $[10,14]$. The maximum power of a wind turbine is achieved by maintaining the tip speed ratio to the optimal reference value. The control method is based on the wind speed measurement. The measured wind speed is used to obtain the reference optimal speed $\omega_{\text {opt }}$ of PMSG. At optimal wind speed, the maximum power of a wind turbine is produced. In the paper this control method is considered in detail.

The aim of the paper is to analyse the converter system of the PMSG generator with a wind turbine under varying wind speed in order to investigate the effectiveness of the wind energy conversion systems. The paper is divided into 7 sections as follows: Section 1 introduction, Section 2 and 3 are dedicated to the description of the mathematical model of wind turbine and PMSG. Section 4 and 5 include description of the vector control system of the machine-side converter and grid-side converter. The simulation results of considered WECS are presented in Section 6. The Section 7 presents the research conclusions.

\section{Wind turbine aerodynamic model}

The analyzed model of a wind turbine is based on the conventional three-bladed horizontal axis wind turbine. The total amount of mechanical power $P_{t}$ captured by the wind turbine and wind turbine mechanical torque $T_{t}$ can be expressed through the following relations $[7-9,11,12]:$

$$
\begin{gathered}
P_{t}=\frac{1}{2} \rho A C_{\mathrm{p}}(\lambda, \beta) v_{w}^{3}, \\
T_{t}=\frac{1}{2} \frac{\rho R A}{\lambda} C_{p}(\lambda, \beta) v_{w}^{2},
\end{gathered}
$$

where: $\rho$ is the air density, $R$ is the radius of the turbine blade, $A=\pi R^{2}$ is the area swept by the rotor blades, $C_{p}$ is the power coefficient of the wind turbine, $\beta$ is the blade pitch angle (in deg), $\mathrm{v}_{w}$ is the wind speed, $\lambda$ is the tip speed ratio, which is defined as: 


$$
\lambda=\frac{\omega_{m} R}{v_{w}},
$$

where $\omega_{m}$ is the angular speed of turbine rotor.

The value of the power coefficient $C_{p}$ is dependent on the tip speed ratio $\lambda$ and blade pitch angle $\beta$. The approximation equation of $C_{p}$ is as follows $[7,9,11]$ :

$$
\begin{aligned}
C_{p}(\lambda, \beta) & =c_{1}\left(\frac{c_{2}}{\lambda_{i}}-c_{3} \beta-c_{4}\right) \cdot \exp \left(-\frac{c_{5}}{\lambda_{i}}\right), \\
\lambda_{i} & =\left(\frac{1}{\lambda+0.089}-\frac{0.035}{\beta^{3}+1}\right)^{-1},
\end{aligned}
$$

where: $c_{1}$ to $c_{5}$ represent coefficients of wind turbine characteristic $\left(c_{1}-0.5, c_{2}-98, c_{3}-0.4\right.$, $\left.c_{4}-5, c_{5}-16.5\right)$.

Figure 2a shows the power coefficient $C_{p}$ as a function of the tip speed ratio $\lambda$ and blade pitch angle $\beta$. The mechanical power generated by the turbine as a function of the rotor angular speed for different wind speeds is shown in Figure $2 \mathrm{~b}$. The optimum power curve $P_{\mathrm{opt}}$ shows how maximum energy can be captured at various wind speeds. As it can be seen, for each value of wind speed a maximum power point exists, where the maximum power is produced by wind turbine.

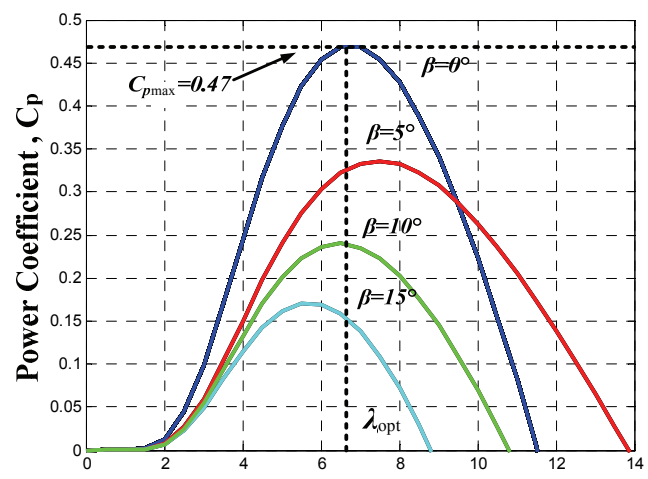

Tip Speed Ratio $\lambda$

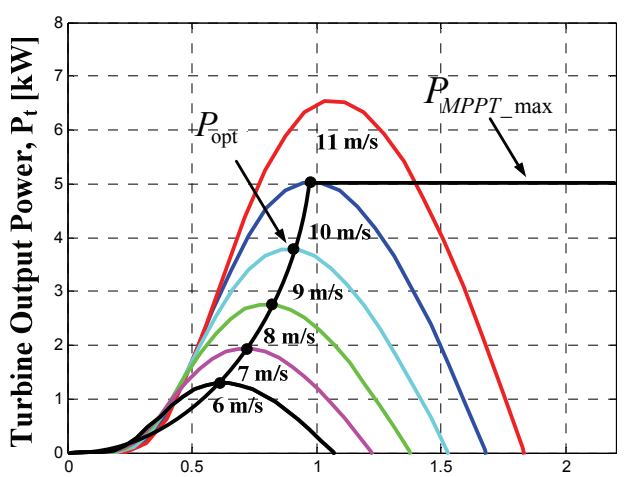

Turbine speed [p.u]

Fig. 2. Characteristics of the wind turbine: a) $C_{p}$ curves as function of $\lambda$ and $\beta$, b) wind turbine power curves as function of rotor angular speed at various wind speeds

\section{Permanent magnet synchronous generator model}

The mathematical model of PMSG is usually based on the following assumptions $[5,6,10,13]$ :

- electrical and magnetically symmetry,

- the magnetic flux is sinusoidally distributed along the air gap, 
- damping windings are not considered,

- the magnetic circuits are linear,

- saturation effect, eddy-currents and hysteresis losses are neglected.

A dynamic model of PMSG has been described in synchronous rotating reference frame, where the $d$-axis is aligning with the direction of the rotor flux and the $q$-axis is $90^{\circ}$ ahead. The mathematical equations of PMSG in this reference frame can be described as follows: $[1,8,9,11,14]$

$$
\begin{gathered}
{\left[\begin{array}{c}
v_{s d} \\
v_{s q}
\end{array}\right]=-R_{s}\left[\begin{array}{c}
i_{s d} \\
i_{s q}
\end{array}\right]-p\left[\begin{array}{c}
\psi_{s d} \\
\psi_{s q}
\end{array}\right]+\omega_{e}\left[\begin{array}{c}
\psi_{s q} \\
-\psi_{s d}
\end{array}\right],} \\
\psi_{s d}=L_{d} i_{s d}-\psi_{P M}, \\
\psi_{s q}=L_{q} i_{s q} .
\end{gathered}
$$

After substitution the equations $(7,8)$ to $(6)$ and conversion the following form is obtained:

$$
p\left[\begin{array}{c}
i_{s d} \\
i_{s q}
\end{array}\right]=\left[\begin{array}{cc}
-\frac{R_{s}}{L_{d}} & \omega_{e} \frac{L_{q}}{L_{d}} \\
-\frac{R_{s}}{L_{q}} & -\omega_{e} \frac{L_{d}}{L_{q}}
\end{array}\right]\left[\begin{array}{c}
i_{s d} \\
i_{s q}
\end{array}\right]+\omega_{e}\left[\begin{array}{c}
0 \\
\psi_{P M}
\end{array}\right]-\left[\begin{array}{c}
\frac{v_{s d}}{L_{d}} \\
\frac{v_{s q}}{L_{q}}
\end{array}\right],
$$

where: $v_{s d}, v_{s q}$ is the components of the stator voltage vector in the $d$ and $q$ axis; $i_{s d}, i_{s q}$ is the components of the stator current vector in the $d$ and $q$ axis, $R_{s}$ is the stator resistance; $\psi_{s d}, \psi_{s q}$ is the direct and quadrature vector components of the stator flux linkages in the $d$ and $q$ axis; $L_{d}, L_{q}$ is the direct and quadrature stator inductances; $\psi_{P M}$ is the flux linkage established by the permanent magnets; $n_{p}$ is the number of pole pairs of PMSG; $p=\mathrm{d} / \mathrm{d} t$ is the differential operator; $\omega_{e}, \omega_{m}$ is the electrical and mechanical angular speed of the PMSG rotor, defined as:

$$
\omega_{e}=n_{p} \cdot \omega_{m} .
$$

The electromagnetic torque of the generator can be expressed as follows:

$$
T_{e}=\frac{3}{2} n_{p} \cdot\left[\psi_{P M} i_{s q}-\left(L_{d}-L_{q}\right) i_{s d} i_{s q}\right] .
$$

For a non-salient-pole machine the stator direct and quadrature inductances $L_{d}$ and $L_{q}$ are approximately equal. In this case the equation of electromagnetic torque can be described in the following form:

$$
T_{e}=\frac{3}{2} n_{p} \psi_{P M} i_{s q}
$$

Equation (12) shows, that the generator torque can be controlled by the quadrature component $i_{s q}$ of the stator current vector. 
The equation of mechanical motion of the wind turbine system is given as:

$$
T_{t}-T_{e}=J \cdot \frac{\mathrm{d}}{\mathrm{d} t} \omega_{m}+B_{f} \omega_{m}
$$

where: $J$ is the total moment of inertia, $B_{f}$ is the coefficient of viscous friction.

\section{The model of control system of machine side converter}

Figure 3 shows the block scheme of the MSC control system $[1,6,14]$. In the control system the optimal control method with the MPPT algorithm has been applied. The MSC control system is based on rotor flux field orientation control (FOC). The angular position $\theta_{e}$ of the rotor flux vector is obtained from the encoder or estimator. The control strategy is based on enforcing the operation at the optimum values of the rotor speed $\omega_{\text {opt }}$ at which the maximum of turbine power is obtained.

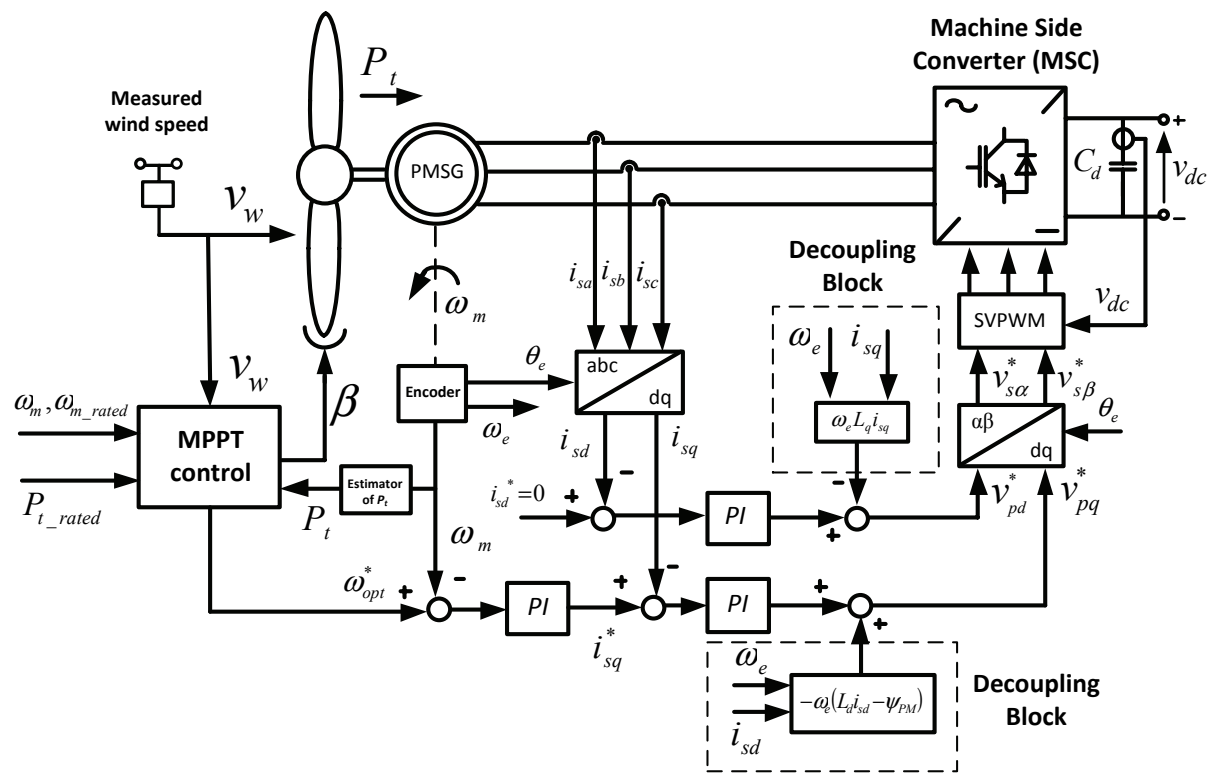

Fig. 3. Control diagram of the Machine Side Converter

The control scheme of MSC consists of an outer control loop and two inner control loops with PI controllers. The outer control loop regulates the generator speed and the inner control loops regulate the stator current vector components to follow the reference values $i_{s q}{ }^{*}, i_{s d}{ }^{*}$. In order to obtain the maximum power from the wind, the turbine should operate at optimum value $\lambda_{\text {opt }}$ by controlling rotational generator speed to follow the optimum speed $\omega_{\text {opt }}$ of wind turbine rotation. According to the power characteristics of the wind turbine (Figure 2a) at any values of wind speed the rotational speed of the turbine rotor $\omega_{m}$ should be regulated to the value $\omega_{\text {opt }}$, which is given as: 


$$
\omega_{\text {ref }}=\omega_{\text {opt }}=\frac{\lambda_{\text {opt }} v_{w}}{R} .
$$

The above equation presents the optimal speed of PMSG in order to obtain the optimal value of tip speed ratio. At optimum wind turbine speed, the turbine is operated at the maximum value of the power coefficient $C_{p \max }$ and produces the maximum mechanical power. The stator current reference $i_{s q}{ }^{*}$ is achieved by the operation of the MPPT control block on the basis of the measured mechanical turbine speed $\omega_{m}$ and the wind speed $v_{w}$. The reference $d q$-axis stator currents $i_{s d}{ }^{*}$ and $i_{s q}{ }^{*}$ are compared with the transformed and measured stator phase currents $i_{s d}$ and $i_{s q}$. The both error signals are sent to two PI controllers. In order to obtain high control performance the applications in the control system of special decoupled circuits are necessary and have been applied. The resultant control signals are the $d q$-axis reference voltages $v_{p d}{ }^{*}$ and $v_{p q}{ }^{*}$ for the MSC. These reference voltages are then transformed to the $\alpha-\beta$-system and are sent to the block of SVPWM (Space Vector PWM modulation). The required switching signals for the machine side converter are generated through the SVPWM block.

An aerodynamic control system has an important role in regulating the wind turbine mechanical power. The optimal pitch angle of blades for wind speeds below the rated value should be approximately equal to zero. The pitch angle should be increased with the growing of wind speed above rated wind speed. The pitch angle controller prevents the possibility of WECS operation in states when the wind turbine mechanical power is greater than rated power.

The maximum value of wind turbine power $P_{t \max }$ is specified at maximum value of $C_{p \max }$ and optimal value of the tip speed ratio $\lambda_{\text {opt }}$ :

$$
P_{t \max }=\frac{1}{2} \rho A C_{p \max }\left(\frac{R \omega_{\mathrm{opt}}}{\lambda_{\mathrm{opt}}}\right)^{3}=P_{M P P T}=K_{\mathrm{opt}} \omega_{\mathrm{opt}}^{3},
$$

where: $K_{\text {opt }}$ is the coefficient of wind turbine.

This equations is used to calculate the mechanical turbine power $P_{t}$ in the estimator block. The characteristic curve $P_{M M P T}$ of the wind turbine system has been shown in Figure 2b. From this curve and equation (14) the reference speed of generator can be developed.

It is assumed that the pitch actuator is a hydraulic or electromechanical device that allows rotating of the turbine blades. The pitch actuator is considered as first-order dynamic system with amplitude and rate limitation. The considered scheme of the turbine blade pitch angle controller is shown in Figure 4 [2, 12, 14].

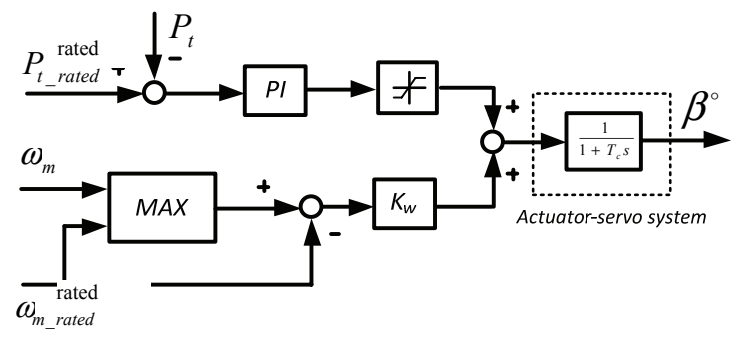

Fig. 4. Wind turbine pitch angle controller 
The pitch angle controller is active only when wind speed is above the rated wind speed. When the wind speed is below the rated value, the pitch angle control system will track the maximum power points. In this controller, the generated turbine power is compared with reference value, which is equal to rated value. The PI controller sets the output value of the pitch angle $\beta$. In the control system of the pitch controller presented in Figure 4, the upper control loop is the basic part, and the lower part is used as correction part with proportional gain $K_{w}$. To prevent the possibility of mechanical damage, when the turbine rotor speed is too high, the blade pitch angle is changed in order to reduce the tip speed ratio $\lambda$ and power coefficient $C_{p}$.

\section{The model of control system of grid side converter}

Figure 5 shows the block scheme of the GSC control system [2,3,15]. The main task of the grid side converter (GSC) is to control the voltage in the DC link and the active and reactive power delivered to the $\mathrm{AC}$ grid, respectively.

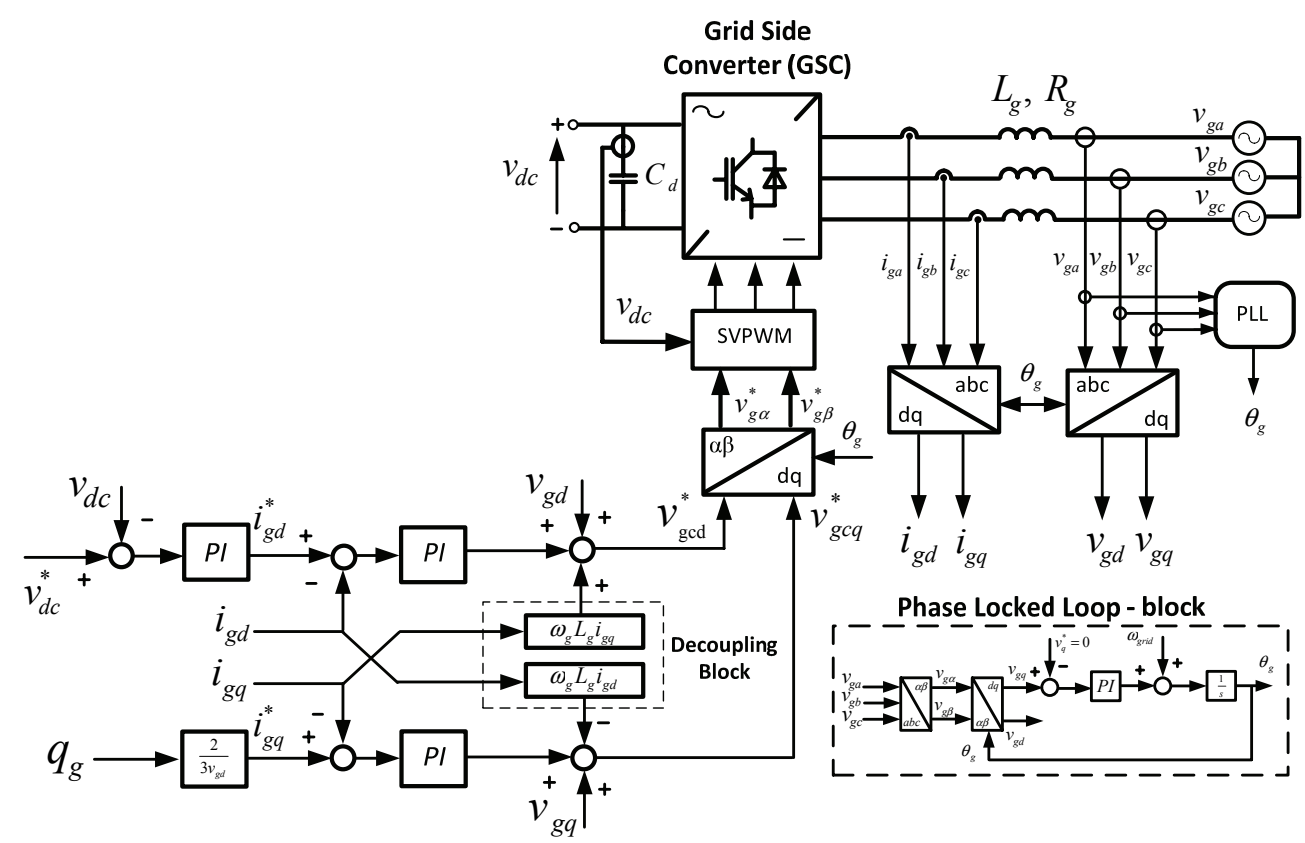

Fig. 5. Control diagram of the Grid Side Converter

The GSC control system is based on grid voltage vector orientation control (VOC). In the VOC system the $d$-axis of the synchronous reference frame is aligned with the grid voltage 
vector. The angle position $\theta_{g}$ of the grid voltage vector is obtained from the PLL (PhaseLocked-Loop) block. The basic scheme of the PLL system is a feedback system with PI-regulator tracking the phase angle [4]. The inputs of the PLL block are the 3-phase grid voltages and the output is the angle $\theta_{g}$ of the grid voltage vector.

The equations of grid side electrical circuits have the following form $[1,10]$ :

$$
\begin{aligned}
& v_{g d}=V_{g}=R_{g} i_{g d}+L_{g} \cdot p i_{g d}-\omega_{g} L_{g} i_{g q}+v_{g c d}, \\
& v_{g q}=0=R_{g} i_{g q}+L_{g} \cdot p i_{g q}+\omega_{g} L_{g} i_{g d}+v_{g c q},
\end{aligned}
$$

where: $v_{g d}, v_{g q}$ is the $d q$-axis components of the grid voltage vector in the grid voltage oriented system, $i_{g d}, i_{g q}$ is the $d q$-axis components of the grid current vector, $v_{g c d}, v_{g c q}$ is the $d q$-axis components of the voltage vector of the grid side converter, $L_{g}, R_{g}$ is the inductance and resistance of the grid filter, $\omega_{g}$ is the angular frequency of the grid voltage.

The grid side converter controls active and reactive power delivered by the converter system to the AC grid. The grid phase currents are measured and transformed into the $d q$-axis currents, $i_{g d}$ and $i_{s q}$. The control strategy of VOC for the grid side converter uses three control loops with PI controllers.

The outer loop of voltage control is responsible for control of the DC link voltage of GSC. The reference grid currents $i_{g d}{ }^{*}$ and $i_{g q}{ }^{*}$ are compared with the measured and transformed grid phase currents $i_{g d}$ and $i_{g q}$. The error signals are sent to two PI controllers. In order to obtain good properties of the control system, the applications of special decoupled circuits are necessary and have been applied in the control system. Thus the active and reactive power can be controlled directly by $i_{g d}$ and $i_{g q}$ respectively. In the typical control systems the reactive power reference is set to zero to perform the operation at unity power factor. The reference voltages ${v_{g p d}}{ }^{*}$ and ${\nu_{g p q}}^{*}$ are then transformed to system $\alpha-\beta$ and are sent to the block of SVPWM.

\section{Simulation results}

The model of a wind energy conversion system with the considered control systems has been implemented in MATLAB/Simulink. The data and parameters of the wind turbine system and PMSG system under the study are given in Tables 1 and 2.

Table. 1. Wind turbine parameters

\begin{tabular}{l|c}
\hline \multicolumn{1}{c|}{ Parameter } & Value \\
\hline Rated power $P_{t}$ & $5 \mathrm{~kW}$ \\
\hline Rotor radius $R$ & $2.8 \mathrm{~m}$ \\
\hline Power coefficient $C_{p \max }$ & 0.47 \\
\hline Air density $\rho$ & $1.225 \mathrm{~kg} / \mathrm{m}^{3}$ \\
\hline
\end{tabular}


Table. 2. Permanent Magnet Synchronous Generators parameters

\begin{tabular}{l|c}
\hline \multicolumn{1}{c|}{ PMSG parameter } & Value \\
\hline Rated power $P_{n}$ & $5 \mathrm{~kW}$ \\
\hline Rated frequency $f_{n}$ & $36 \mathrm{~Hz}$ \\
\hline Rated torgue $T_{n}$ & $200 \mathrm{Nm}$ \\
\hline Stator resistance $R_{s}$ & $1.5 \Omega$ \\
\hline Stator $d q$-axis inductance $L_{d}, L_{q}$ & $14.04 \mathrm{mH}$ \\
\hline Stator rated phase current $I_{s n}$ & $15 \mathrm{~A}$ \\
\hline Number of pole pairs $p_{b}$ & 8 \\
\hline
\end{tabular}

The simulation results are presented in Figures 6-14. Figure 6 shows the considered wind speed variation during the period of the $10 \mathrm{~s}$ simulation. The rated wind speed has been set as equal to $10 \mathrm{~m} / \mathrm{s}$.

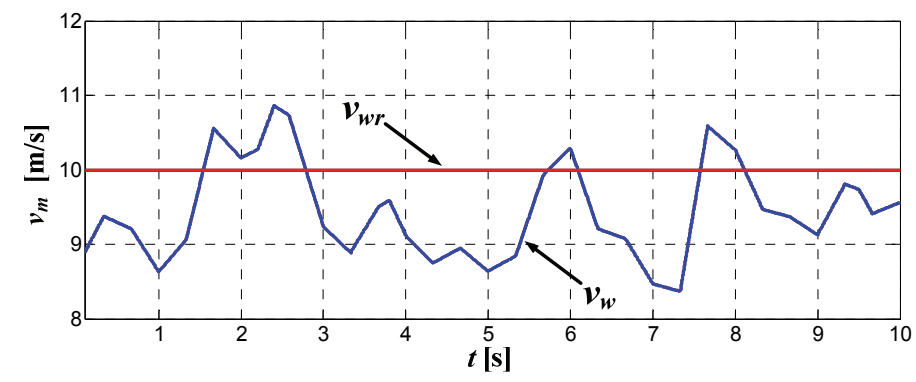

Fig. 6. Waveforms of rated $v_{w r}$ and real wind speed $v_{w}$

Figure 7 shows the waveforms of optimal $\omega_{\text {opt }}$ and the measured $\omega_{m}$ angular speed of PMSG. As it can been seen, the waveform of the generator speed $\omega_{m}$ is accurately adjusted to the waveform of the optimal speed $\omega_{\text {opt }}$.

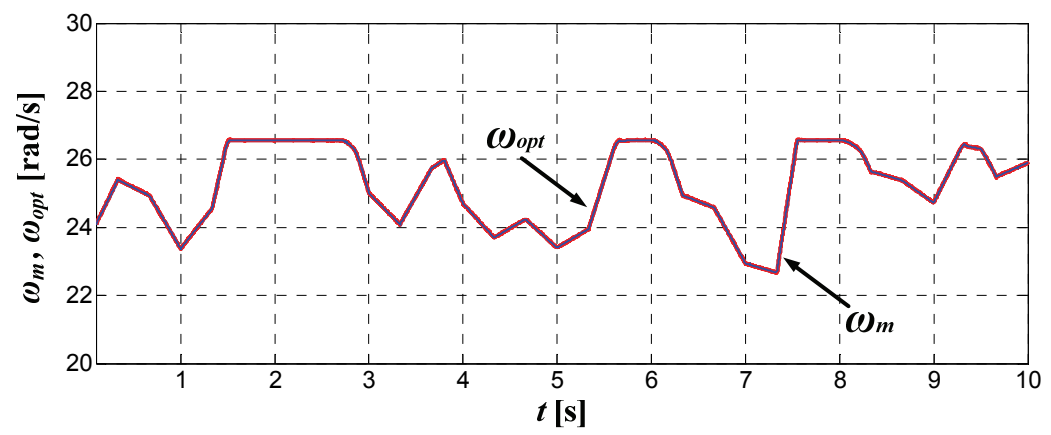

Fig. 7. Waveforms of measured $\omega_{m}$ and reference speed $\omega_{\text {opt }}$ of PMSG

The waveforms of the tip speed ratio, blade pitch angle and power coefficient at various wind speeds have been presented in Figures 8-9. The operation of the blade pitch control is 
presented in detail in Figure 8. When the system operates under the rated wind speed, the obtained values of the coefficient $C_{p}$ and the tip speed ration $\lambda_{\text {opt }}$ are maintained to its maximum value $\left(C_{p \max }=0.47, \lambda_{\text {opt }}=6.5\right)$ and the pitch angle $\beta$ is equal to zero. However if the wind speed reaches the rated value $\left(\mathrm{v}_{w}=10 \mathrm{~m} / \mathrm{s}\right)$ the $C_{p}$ and $\lambda_{\text {opt }}$ are decreased due to the operation of the pitch angle control.

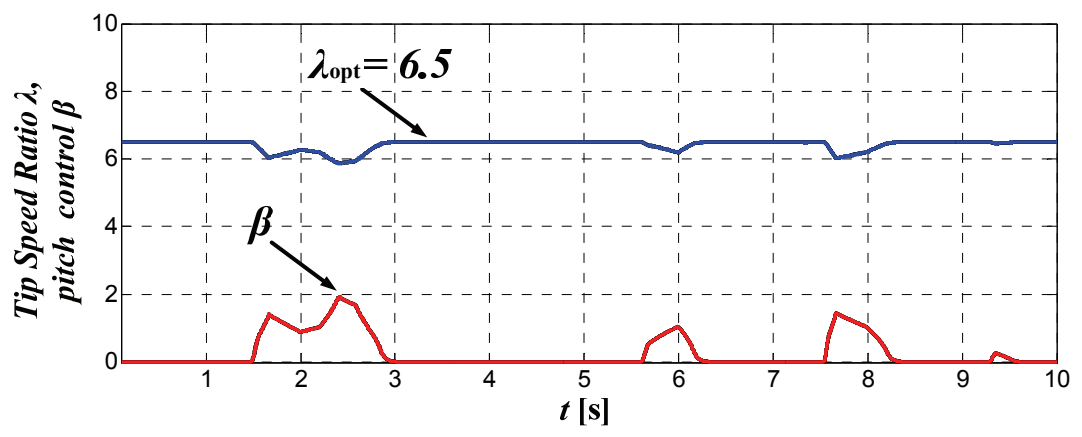

Fig. 8. Waveforms of tip speed ratio $\lambda$ and blade pitch angle $\beta$

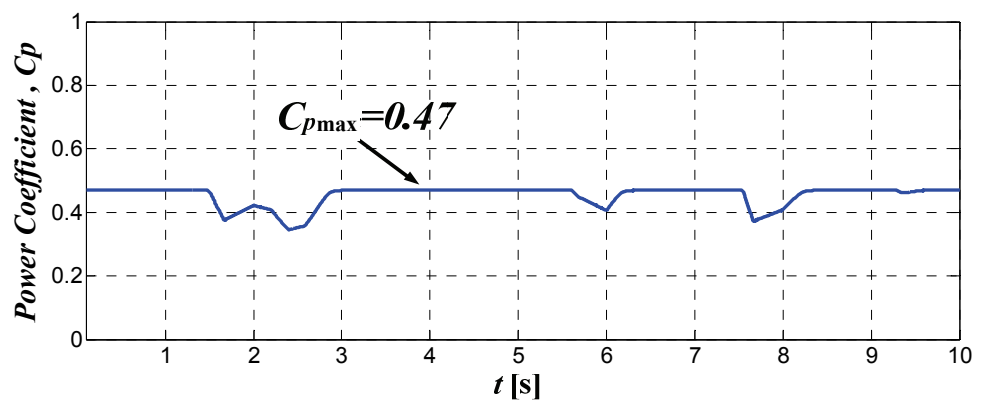

Fig. 9. Waveform of power coefficient of wind turbine $C_{p}$

Figure 10 presents the time variation of mechanical power of the wind turbine. As it can be seen, the maximum value of wind turbine power is maintained at a reference value and does not exceed the maximum power.

The time variations of the mechanical torque $T_{t}$ of the wind turbine and the electromagnetic torque $T_{e}$ of the PMSG generator are presented in Figure 11, respectively. In this case the electromagnetic torque of PMSG responses accurately to the time changes of wind speed.

Figure 12 presents the responses of the stator current vector components $i_{s d}, i_{s q}$ caused by the variation of wind speed. The component $i_{s d}$ of the stator current vector is kept at zero values. The responses of component $i_{s q}$ of the stator current vector have virtually similar waveforms as the variations of the wind speed.

The Figure 13 presents the waveform of the voltage $v_{d c}$ in DC link. The instantaneous values of voltage $v_{d c}$ are quite constant at variations of wind speeds. 


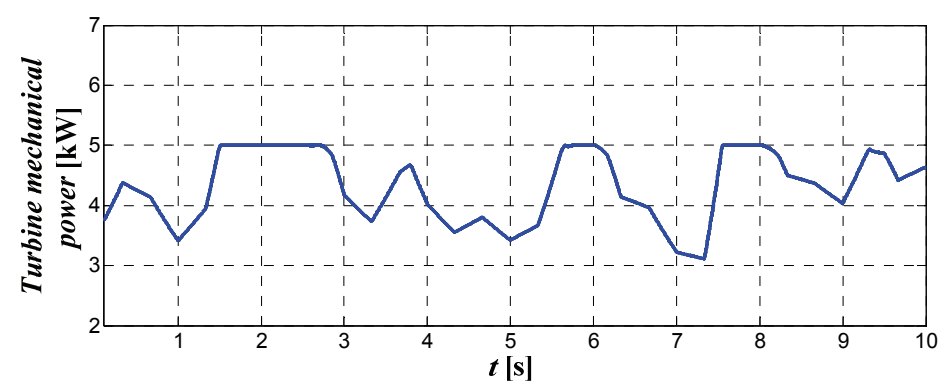

Fig. 10. Waveform of mechanical power $P_{t}$ of wind turbine

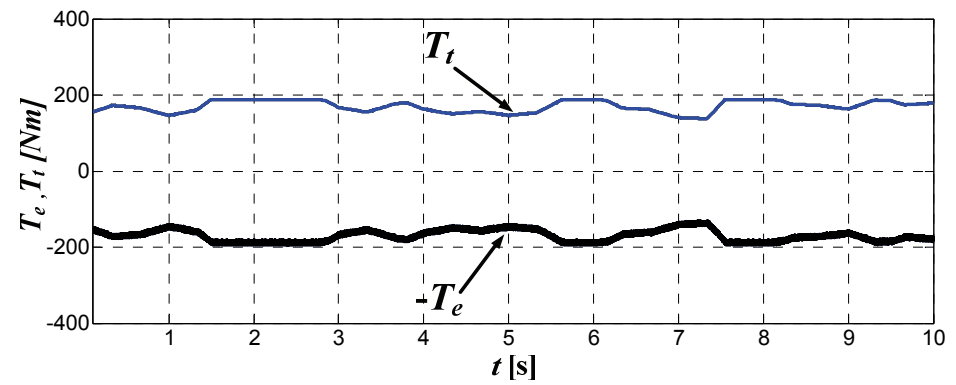

Fig. 11. Waveforms of electromagnetic torque $T_{e}$ of PMSG and mechanical torque $T_{t}$ of wind turbine

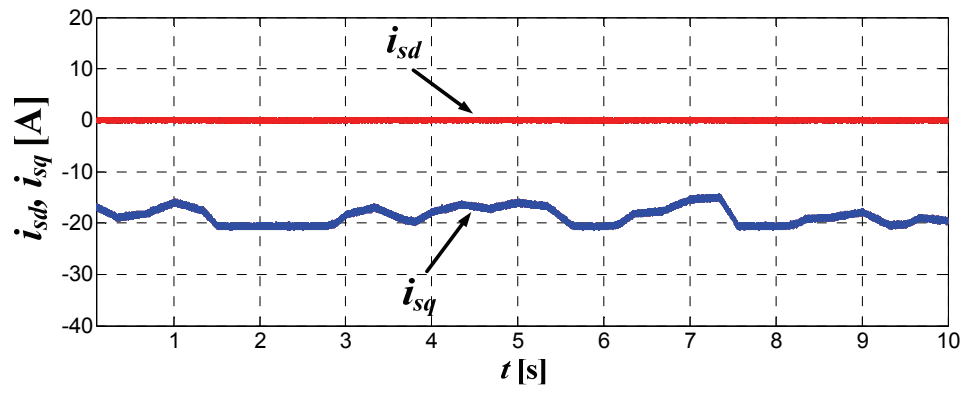

Fig. 12. Waveforms of stator current vector components $i_{s d}, i_{s d}$ of PMSG

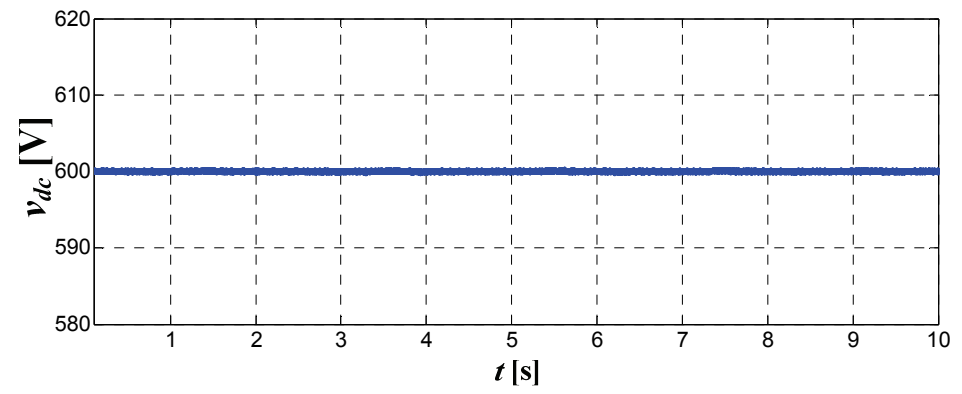

Fig. 13. Waveform of DC link voltage 
Figure 14 shows the components $i_{g d}$ and $i_{g q}$ of the grid current vector. From Figure 14, it can be seen, that the component $i_{g q}$ is maintained at zero value. It means that only the active power generated by WECS is fully delivered to the AC grid, while the reactive power is equal to zero.

Figure 15 presents the waveforms of the phase grid voltage and grid current. It can be noticed, that the waveforms of grid phase current and phase voltage are in phase.

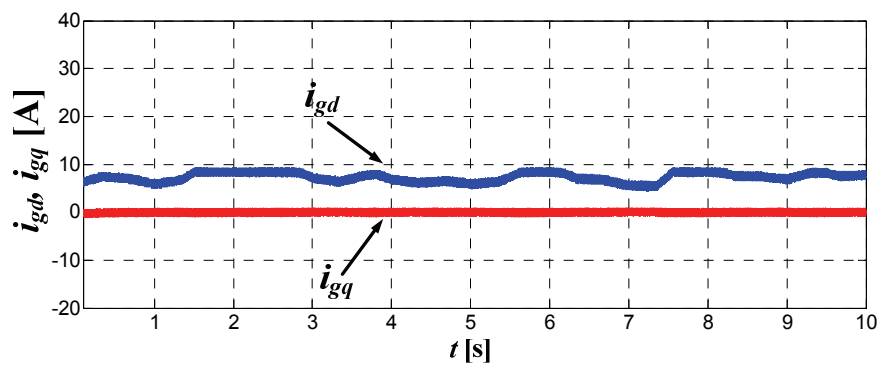

Fig. 14. Waveforms of grid current vector components $i_{g d}, i_{g q}$

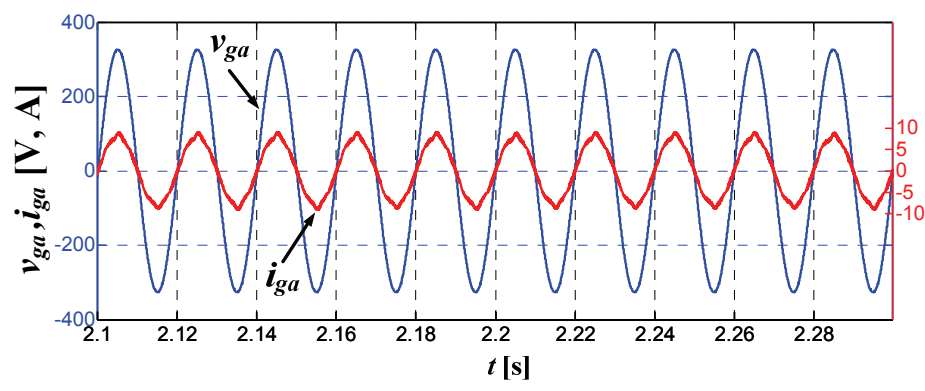

Fig. 15. Waveforms of grid phase voltage $v_{g a}$ and current $i_{g a}$

\section{Conclusions}

The paper presents the dynamic modeling and control structure approach of a wind turbine system with variable speed direct-driven PMSG. The considered control algorithm is based on the vector control to regulate the machine side converter and grid side converter. In this paper two methods of vector control have been investigated: FOC for the MSC converter and VOC for the GSC converter.

FOC allows to generate the maximum power of the wind turbine in order to obtain the optimal operation at generation of the maximum turbine mechanical power. The simulation results have shown, that $C_{p}$ should be kept at its maximum value despite the changes of wind speed. Additionally the pitch control scheme is proposed to achieve limitation of the maximum turbine power and to the prevent mechanical damage of the wind turbine.

The VOC control of GSC enables to keep the DC link voltage to a reference value and to adjust the active and reactive power delivered to the $\mathrm{AC}$ grid. Reactive power generated by the wind turbine system is usually controlled to zero. 
The presented simulations confirmed that the considered WECS system shows a high performance level. The systems with PMSG have many advantages: operation at high power factor, high efficiency and high torque to current ratio. The simulation results show the good properties of the control system for the wind turbine with the direct-driven PMSG generator.

\section{References}

[1] Daoud A.A., Dessouky S.S., Salem A.A., Control scheme of PMSG based wind turbine for utility network connection, 10th International Conference on Environment and Electrical Engineering (EEEIC), pp. 1-5 (2011).

[2] Errami Y., Maaroufi M., Ouassaid M., Modeling and control strategy of PMSG based variable speed wind energy conversion system, International Conference on Multimedia Computing and Systems (ICMCS), pp. 1-6 (2011).

[3] Freire N., Estima J., Cardoso A., A comparative analysis of PMSG drives based on vector control and direct control techniques for wind turbine applications, Przegląd Elektrotechniczny, vol. 88, no. 1, pp. 184-187 (2012).

[4] Wu B., Yongqiang L., Navid Z., Samir K., Power conversion and control of wind energy, A John Wiley \& Sons, INC., Publication (2011).

[5] Gajewski P., Pieńkowski K., Modeling and analysis of wind power system with PMSG generator, Prace Naukowe Instytutu Maszyn, Napędów i Pomiarów Elektrycznych Politechniki Wrocławskiej (in Polish), vol. 69, no. 33, pp. 207-221 (2013).

[6] Kun H., Guo-zhu Ch., A novel control strategy of wind turbine MPPT implementation for directdrive PMSG wind generation imitation platform, IEEE 6th International Conference on Power Electronics and Motion Control, IPEMC '09, pp. 2255-2259 (2009).

[7] Rolan A., Lina A., Vazquez G., Aguilar D., Azevedo G., Modeling of a variable speed wind turbine with a permanent magnet synchronous generator, IEEE Transaction on Industrial Electronics, pp. 734-739 (2009).

[8] Gajewski P., Pieńkowski K., Analysis of wind turbine system with PMSG generator, Maszyny Elektryczne - Zeszyty Problemowe (in Polish), vol. 103, no. 3, pp. 31- 36 (2014).

[9] Mayouf M., Abdessemed R., Comparative Study of a Small Size Wind Generation System Efficiency for Battery Charging, Serbian Journal of Electrical Engineering, vol. 10, no. 2, pp. 261-274 (2013).

[10] Liyong Y., Peie Y., Zhenguo Ch., Zhigang Ch., Zhengxi L., A novel control strategy of power converter used to direct driven permanent magnet wind power generation system, International Conference on Power Electronics and Intelligent Transportation System (PEITS), vol. 1, pp. 456-459 (2009).

[11] Molina M.G., Sanchez A.G., Lede A.M.R., Dynamic modeling of wind farms with variable-speed direct-driven PMSG wind turbines, Transmission and Distribution Conference and Exposition: Latin America (T\&D-LA), 2nd IEEE/PES, pp. 816-823 (2010).

[12] Muyeen S.M., Takahashi R. Murata T., Tamura J., A Variable Speed Wind Turbine Control Strategy to Meet Wind Farm Grid Code Requirements, IEEE Transactions on Power Systems, vol. 25, no. 1, pp. 331-340 (2010).

[13] Wen Ch., Lu G., Wang P., Li Z., Liu X., Vector control strategy for small-scale grid-connected $P M S G$ wind turbine converter, International Conference and Exhibition on Innovative Smart Grid Technologies (ISGT Europe), 2nd IEEE PES, pp. 1-7 (2011).

[14] Errami Y., Maaroufi M., Ouassaid M., A MPPT vector control of electric network connected wind energy conversion system employing PM synchronous generator, International Renewable and Sustainable Energy Conference (IRSEC), pp. 228-233 (2013).

[15] Mahersi E., Khedher A., Faouzi Mimouni M., The wind energy conversions system using PMSG controlled by vector control and SMC strategies, International Journal of Renewable Energy Research, vol. 3, no. 1, pp. 41-50 (2013). 